\title{
La forja del patrimonio de Francisco Romero Robledo ${ }^{1}$
}

\section{How Francisco Romero Robledo forged his patrimony}

\author{
Mercedes Fernández Paradas \\ Universidad de Málaga \\ paradas@uma.es \\ Francisco José García Ariza \\ Investigador independiente \\ fjgara05@hotmail.com
}

Fecha de recepción: 04-01-2019

Fecha de aceptación: 04-06-2019

\section{RESUMEN}

Esta investigación analiza una faceta hasta ahora desconocida sobre Francisco de Paula Romero Robledo, una de las figuras más relevantes de la política nacional española de la segunda mitad del ochocientos y comienzos del novecientos. Nos referimos a cómo forjó su patrimonio, sirviéndose en buena medida de sus relaciones de parentesco, clientelares y de amistad. Las vías de conformación de su patrimonio fueron las siguientes: 1) Las herencias recibidas; 2) Su matrimonio con María Josefa Zulueta Samá, hija de Julián Zulueta y Amondo, comerciante de esclavos y fabricante de azúcar en Cuba; 3) Las compras de fincas rústicas y urbanas; y, 4) Su participación en empresas con actividades muy diversas, entre las que destacó sobremanera la Sociedad Azucarera Antequera, empresa que fundó en 1890. Asimismo, hemos constatado su interés por gestionar su patrimonio. Nos hemos basado principalmente en documentación inédita, conservada en el Archivo Histórico Municipal de Antequera y el Archivo de Protocolos Notariales de Madrid.

Palabras clave: Biografía política, patrimonio, familia, redes clientelares.

Topónimos: España

Periodo: Siglo XIX, Restauración borbónica.

\section{ABSTRACT}

This research analyses a previously unknown facet of Francisco de Paula Romero Robledo, one of the most significant figures in Spanish national politics during the second half of the $19^{\text {th }}$ and

1 Agradecemos a José Escalante Jiménez, Director del Archivo Histórico Municipal de Antequera, su ayuda en la consulta de los diferentes fondos de dicho centro de documentación relacionados con Francisco Romero Robledo. También a los editores de la Revista y a los evaluadores anónimos que han contribuido decisivamente a mejorar el artículo. 
the early $20^{\text {th }}$ century. In reference to how he forged his patrimony, assisted by family connections, clientelism and friendships.

The process of formation of his patrimony was as follows: 1) Inheritances received; 2) His marriage to Josefa Zulueta Samá, daughter of Julián Zulueta y Amondo, slave trader and sugar producer in Cuba; 3) Purchases of rural and urban properties; and 4) Participation in companies with very diverse activities, notably the Antequera Sugar Company, which he founded in 1890. There is also confirmation of his interest in administering his patrimony. This study is based on unpublished documents, preserved in the History Archives of Antequera and the Notarial Protocol Archives of Madrid.

Key words: Political biography, patrimony, family, clientelism.

Place names: Spain.

Period: XIX century, Bourbon Restoration.

\section{INTRODUCCIÓN}

La biografía del antequerano Francisco de Paula Romero Robledo (1838-1906) resulta apasionante por su relevancia política a nivel nacional, especialmente desde inicios de los años 1860 hasta su fallecimiento en 1906. Los trabajos publicados sobre este personaje se han centrado en su participación en la vida política nacional, quedando minimizados o incluso desconocidos otros aspectos de su biografía ${ }^{2}$. En su época se fraguó una imagen a la que contribuyó decisivamente el escritor Antonio Linares Rivas, quien lo describió como una persona frívola. Fueron famosas sus veladas nocturnas, duelos y sus amistades de lo más variopintas ${ }^{3}$. Esta es, en buena medida, la imagen que ha quedado de Francisco Romero Robledo.

En esta investigación nos centramos en otros aspectos de su biografía que ponen de manifiesto unos intereses que le permitieron acumular una cuantiosa fortuna, pues, en definitiva, fue un emprendedor que supo trabar la actividad empresarial con la vida política, siempre para consolidar e incrementar su patrimonio. Por otra parte, existe otra faceta interesante en su biografía, la defensa que realizó del patrimonio histórico artístico de su ciudad $^{4}$, y también su afición como poeta ${ }^{5}$.

Procede, por tanto, analizar los mecanismos con los que Romero Robledo amasó un patrimonio de extraordinaria envergadura. Las vías de conformación fueron las siguientes: 1) Las herencias recibidas; 2) Su matrimonio con María Josefa Zulueta Samá, hija de

2 Con la llegada de la Restauración Romero Robledo se afilió al partido conservador de Antonio Cánovas del Castillo. Durante dicho periodo fue Ministro de Gobernación, Ultramar, Gracia y Justicia y Presidente del Congreso de los Diputados. J. Ayala Pérez, Un político de la Restauración Romero Robledo, Antequera, Biblioteca Antequerana de la Caja de Ahorros y Préstamos de Antequera, 1974; A. Parejo Barranco, Francisco Romero Robledo. Último político romántico. Ingenio de la Restauración (Antequera, 1838-Madrid, 1906), Antequera, Ayuntamiento de Antequera, 2006; M. J. Ramos Rovi, Romero Robledo y el parlamentarismo español, Madrid, Congreso de los Diputados, Dirección de Estudios, Análisis y Publicaciones, 209; y Diccionario biográfico de Parlamentarios Andaluces (1876-1923), Sevilla, Universidad de Sevilla, 2013, pp. 27-43 y 454-455.

3 A. Parejo Barranco, Francisco Romero..., pp. 15-16.

4 Información proporcionada por José Escalante Jiménez, responsable del Archivo Histórico Municipal de Antequera.

5 Archivo Histórico Municipal de Antequera (AHMA), Fondo de Archivos Familiares (FAF), Archivo Romero Robledo (ARR), signatura 8. 
Julián Zulueta y Amondo, comerciante de esclavos y fabricante de azúcar en Cuba; 3) Las compras de fincas rústicas y urbanas; y, 4) Su participación en empresas con actividades muy diversas, de las que destacó sobremanera la Sociedad Azucarera Antequera, empresa que fundó en $1890^{6}$. Partimos de la hipótesis de que en la toma de decisiones para formar su patrimonio desempeñaron un papel clave sus relaciones de parentesco, clientelares y de amistad.

Este estudio se ha basado en el análisis de documentación del Archivo de Protocolos Notariales de Madrid y el Archivo Histórico Municipal de Antequera, hasta ahora inédita ya que no ha sido consultada por sus biógrafos, así como en el Archivo Nacional de Cuba. Del Archivo Histórico Municipal de Antequera hemos consultado el Fondo de Protocolos Notariales, del Fondo de Archivo Familiares el Archivo Romero Robledo y del Fondo de Archivos de Empresa el Archivo de la Sociedad Azucarera Antequerana.

\section{SU FORTUNA Y ACTIVIDADES ECONÓMICAS}

\subsection{Las herencias recibidas y las propiedades adquiridas antes de su matrimonio}

Los inicios y ampliación del patrimonio de Francisco Romero Robledo (Figura 1) fueron posibles merced a las herencias recibidas y la compra de propiedades que realizó a familiares cercanos. Por este motivo, antes de analizarlos, es preciso conocer estos vínculos familiares.

Francisco Romero Robledo era bisnieto de Mateo Robledo Rodríguez y María de Castilla, de cuyo unión nacieron Gabriel, Manuel y Vicente Robledo Castilla ${ }^{7}$. En 1803 Vicente contrajo nupcias con María de los Remedios Checa Ruiz (1770-1856), hija de Nicolasa Navarrete y Antonio Checa Pérez, fabricante de curtidos y propietario de tierras. Del matrimonio de Vicente y Remedios nacieron Antonio, José, Dolores, Vicente y Teresa Robledo Checa (1814-1840). Esta última, contrajo nupcias con Matías Romero Mantilla $(1810-1878)^{8}$. Tuvieron tres hijos, Antonio (1836), que murió párvulo, Francisco de Paula (1838), y Concepción Romero Robledo (1840). Teresa falleció en el parto de Concepción. La abuela materna de Francisco de Paula, María de los Remedios Checa Ruiz, se encargó de su crianza. Su tío Vicente Robledo Checa (1810-1884) fue responsable de su educación. El padre, Matías, quedó en segundo plano, en ello pudo influir que fuese un mediano propietario, mientras su madre formaba parte de una de las familias más acaudaladas e influyentes de Antequera ${ }^{9}$.

6 F. J. García Ariza, "La construcción del Ingenio San José", Revista de Estudios Antequeranos, 19-20 (20162017), pp. 39-116.

7 Vicente Robledo Castilla (1764-1849) fue elegido regidor de Antequera en las elecciones municipales de finales de 1833. Su fortuna se fundamentó sobre su actividad como fabricante de tejidos y las compras de tierras de la Iglesia y el ayuntamiento, convirtiéndose en uno de los mayores propietarios de tierras. M. Fernández Paradas, Propios, Arbitrios y Comunales. El patrimonio territorial del Concejo de Antequera (siglos XV-XIX), Málaga, CEDMA, 2004, p. 208; A. J. Pinto Tortosa, El medio agrario andaluz ante la llegada del liberalismo: las revoluciones de 1835 y 1836 en Antequera, Antequera, Ayuntamiento de Antequera, 2009, pp. 34-35.

8 Matías Romero era hijo de Matías Romero Berrocal, vecino de Álora. Suplemento de la Hojita Parroquial de Álora, 1 de julio de 1914.

9 A. Parejo Barranco, Francisco Romero..., p. 12. R. Talavera Quirós, Familias Antequeranas, ejemplar mecanografiado, 2014, pp. 1.147 y 1.157. 
Figura 1. Francisco Romero Robledo

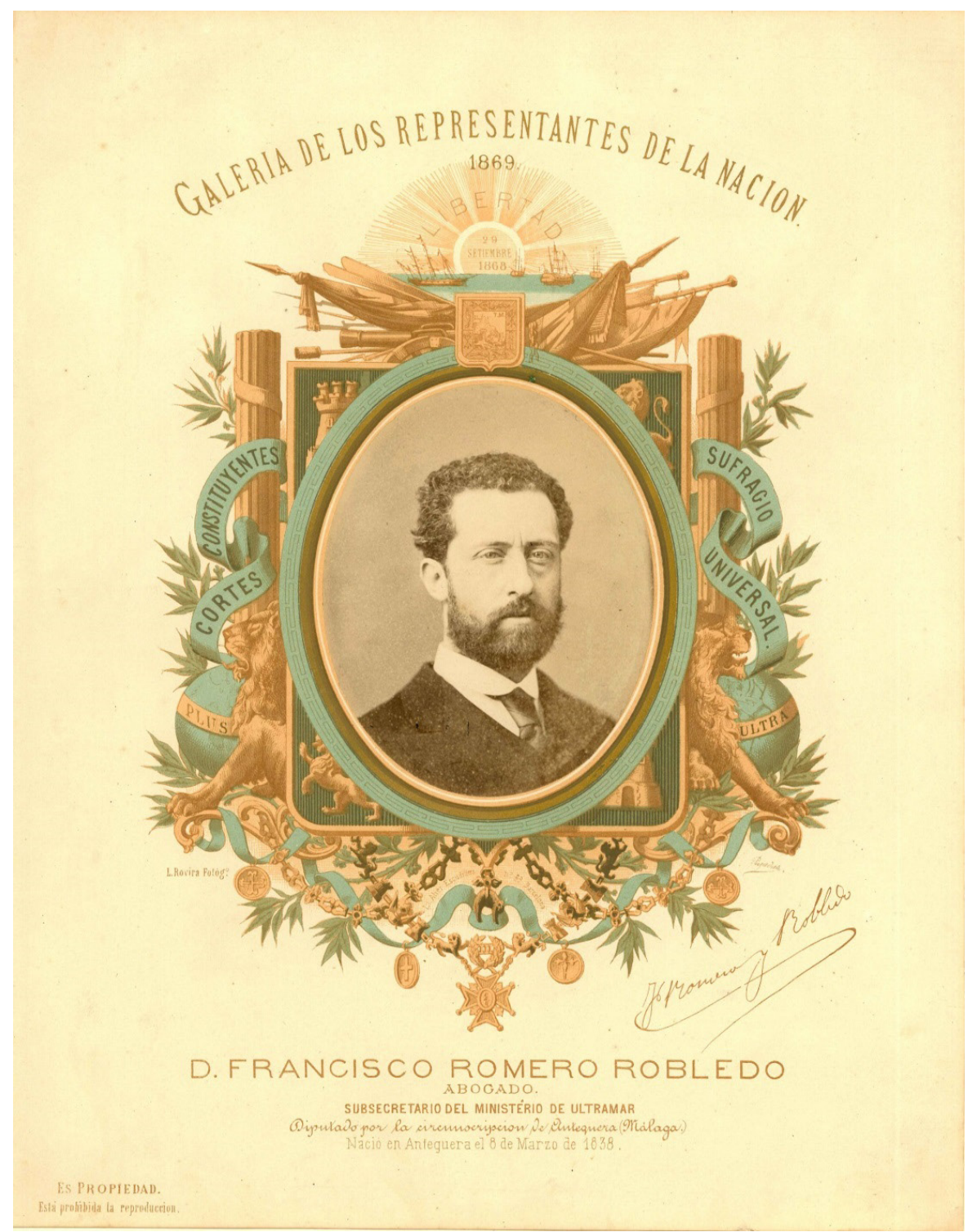

Fuente: AHMA.

El inicio su carrera política se lo debió a su tío Vicente. La empezó a finales del reinado de Isabel II, en el período correspondiente al "Gobierno Largo" de O'Donnell (junio de 1858 a marzo de 1863). En 1862 logró su primera acta de diputado por la Unión Liberal. Se presentó por la circunscripción electoral de Antequera. Hasta entonces, Álora y Antequera habían sido controladas políticamente por otra familia, los Márquez Navarro, cuyo poder se centraba en el municipio de Álora. Vicente Robledo movió todas sus amistades para conseguirlo. La lucha con los Márquez en las elecciones de 1862 y en las de 1864 dieron a Antequera la preeminencia que hasta entonces había tenido Álora ${ }^{10}$.

Hasta su muerte, Vicente Robledo Checa (1810-1886) (Figura 2), amigo íntimo de Antonio Cánovas del Castillo ${ }^{11}$, aconsejó a su sobrino en los asuntos políticos y

10 A. Parejo Barranco, "Revolución liberal y elites locales. Dos ejemplos antequeranos de la segunda mitad de siglo XIX", en Antequera. Memorias de una época. Cincuenta años de la vida de una ciudad a través de la fotografía, Antequera, Junta de Andalucía, 1998, pp. 162-163. M. J. Ramos Rovi, Diccionario..., p. 57.

11 J. L. Comellas, Cánovas del Castillo, Barcelona, Ariel, 1997. 
económicos, y en lo personal ${ }^{12}$. Fue uno de los personajes más relevantes de la Antequera del Ochocientos. Heredó los negocios agrarios e industriales de su padre, Vicente Robledo Castilla, cuya gestión compatibilizó con su trabajo de escribano público ${ }^{13}$. Asimismo, fue uno de los prohombres del partido conservador. En las elecciones generales de 1871 y 1872 logró la mayoría absoluta por el distrito de Torrox (Málaga). Lo mismo sucedió en los comicios de 1876 por el distrito electoral de Antequera ${ }^{14}$. En suma, Vicente era el prototipo de cacique con poderosa influencia económica y política en la comarca de Antequera y en otras localidades de la provincia de Málaga.

Figura 2. Retrato de Vicente Robledo Checa, señalando una imagen de Francisco Romero Robledo

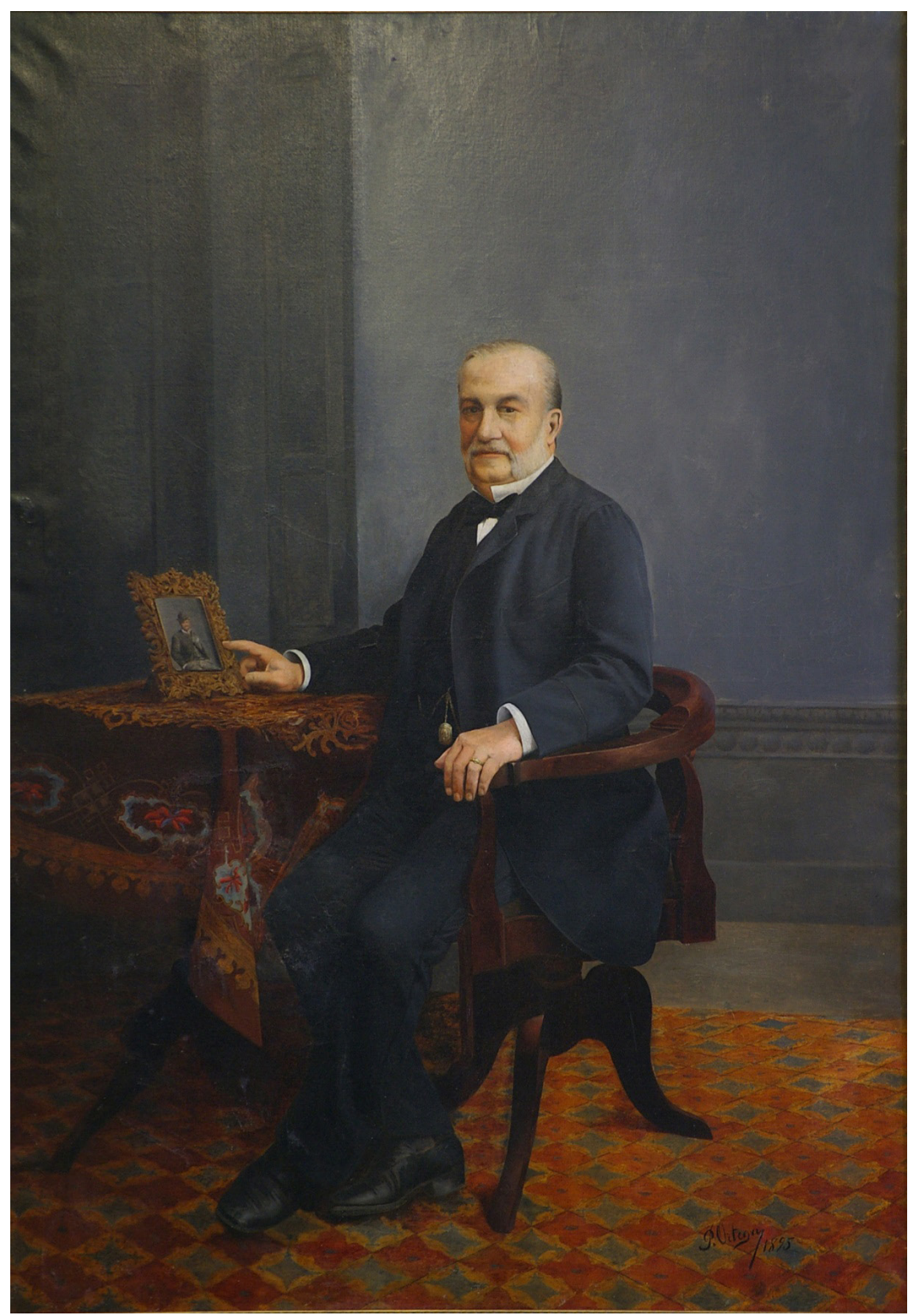

Fuente: AHMA.

12 Dicha confianza se puso de manifiesto en: AHMA, Fondo de Protocolos Notariales (FPN), Notaría de Juan Antonio Betes Díaz, Poder de Francisco Romero Robledo a favor de Vicente Robledo y Checa, 7-10-1878, leg. 2.917, ff 905r-907r.

13 J. Escalante Jiménez, Los escribanos en Antequera. Un análisis global (1475-1868), Tesis Doctoral, Universidad de Málaga, 2015, p. 165.

14 M. J. Ramos Rovi, Diccionario..., p. 432. 
Vicente Robledo Checa trató a Francisco Romero Robledo (Figura 2) como si fuese su hijo. Se preocupó porque recibiese una sólida formación que sufragó, eligiendo centros educativos de prestigio. Francisco Romero cursó sus primeros estudios en las Escuelas Pías de Archidona, el Bachillerato en el Colegio San Felipe Neri de Málaga. El curso 1853-1854 se matriculó en la Facultad de Derecho de Madrid, donde obtuvo excelentes calificaciones. En mayo de 1859 concluyó la licenciatura en Derecho Civil y Canónico. Ese mismo año ingresó en el Colegio de Abogados de Madrid y la Academia de Jurisprudencia. Dos años después se doctoró ${ }^{15}$. Prueba del fuerte vínculo entre tío y sobrino es que, como analizaremos más adelante, en la etapa de su matrimonio con María Josefa de Zulueta lo trató de manera más favorable que al resto de herederos.

Veamos a continuación cómo se fraguó buena parte de la fortuna inicial de Romero Robledo en base a vínculos familiares. Hasta su toma de posesión como diputado en marzo de 1863, parece ser que no había tenido remuneración alguna. Por entonces, ya había recibido las herencias de su abuelo, Vicente Robledo Castilla en 1850 y de su madre Teresa Robledo Checa en 1857. De Vicente Robledo Castilla heredó bienes valorados en 65.570 reales, consistentes en un molino de aceite (18.058 reales) y un solar (5.381 reales) en la ciudad de Antequera, una parcela de 9,50 aranzadas de olivar (28.500 reales) y 13.811 reales. Los bienes se le adjudicaron en $1868^{16}$. De Teresa Robledo Checa recibió un solar en la ciudad de Antequera tasado en $1.345^{\prime} 25$ pesetas $^{17}$.

Las adquisiciones de propiedades que efectuó antes de contraer matrimonio en 1875 fueron a familiares. A su tío Vicente Robledo Checa le compró: su fábrica del "Henchidero" en 1862, se deshizo de ella ${ }^{18}$ en 1870; el cortijo de "El Romeral" de 433 hectáreas de tierra de labor, plantado de olivar, viña y huerta con frutales, valorado en 175.000 ptas.; y el caserío de "Robledo" en 1870, en 20.000 ptas. Poco antes de casarse compró a su tía María Remedios Robledo el molino harinero de los "Álamos", tasado en 10.000 ptas.

15 AHMA, FAF, ARR, signatura 8. A. Parejo Barranco, Francisco Romero..., p. 13. El político liberal Germán Gamazo Calvo (1840-1901) también estudió Derecho, se doctoró y fue miembro del Colegio de Abogados de Madrid y de la Academia de Jurisprudencia. Como Romero Robledo fue Ministro de Ultramar y formaron parte del Partido Constitucional. E. Calzada del Amo, Germán Gamazo (1840-1901). Poder político y redes sociales en la Restauración, Madrid, Marcial, Pons, 2011, pp. 39, 51-52, 57, 86, 120, 125 y 175. Más adelante nos referiremos a Antoni Sedó i Pàmies, quien también perteneció a la Academia de Jurisprudencia. Romero Robledo fue accionista de A. Sedó y Compañía. G. Dorel-Ferré, Les colònies industrials a Catalunya. El cas de la Colònia Sedó, Barcelona, L'Abadia de Montserrat, 1992, p. 278.

16 AHMA, FPN, Escribanía de Miguel Talavera, Inventario y aprecio de los bienes relictos por fallecimiento de D. Vicente Robledo y Castilla, 12-6-1850, leg. 2.447, folios 423r-546rv. Romero Robledo, de su abuelo Vicente heredó bienes valorados en 65.151 reales, entre ellos cabe destacar 1 solar y 1 molino de aceite en la ciudad, así como 9'50 aranzadas de olivar. Los bienes se le adjudicaron en 1868. AHMA, FPN, Escribanía de Miguel Talavera, Matías Romero Mantilla compadre de su menor hijo dn. Francisco de Paula Romero Robledo y dn. José María Bores y doña Concepción Romero su consorte. Participación de bienes de Vicente Robledo y Castilla, 23-6-1857, leg. 2.868, folios 487r-489v; y, Escribanía de Juan Antonio Betes Díaz, Escritura de adjudicación de los bienes que procedentes de la herencia de su abuelo materno Don Vicente Robledo y Castilla hacen los señores Francisco y María de Concepción Romero y Robledo, 17-9-1868, leg. 2.902, folios 1.270r-1.272r.

17 AHMA, Fondo de Archivos de Empresa (FAE), Archivo de la Sociedad Azucarera Antequera (ASAA), leg. 226, carpeta 2, Partición de bienes al fallecimiento de Josefa Zulueta, 27-2-1897.

18 A. Parejo Barranco, Historia de Antequera, Antequera, Biblioteca Antequerana de la Caja de Ahorros, 1987, p. 350. 


\subsection{El impacto de su matrimonio en su patrimonio}

La vida de Romero Robledo dio un giro el 4 de diciembre de 1875 cuando contrajo nupcias con María Josefa Zulueta Samá (1845-1896) ${ }^{19}$ en Madrid ${ }^{20}$. Era hija de Julián de Zulueta y Amondo (1814-1878) ${ }^{21}$ y de su primera esposa, Francisca Dolores Samá y Mota, hija de una destacada familia catalana. Julián de Zulueta había nacido en Álava, con 18 años marchó a Cuba, donde se convirtió en un miembro relevante de la elite cubana. Se dedicó al comercio, la banca, el tráfico de esclavos y a la fabricación de azúcar de caña, en cuyos ingenios introdujo tecnología puntera ${ }^{22}$. Había afinidad ideológica entre Julián Zulueta y Francisco Romero, ambos eran conservadores y pro-peninsulares. En relación a Cuba, Zulueta no aceptaba cambio alguno o reforma en el estatus político de la Isla ${ }^{23}$.

Del matrimonio nacieron cinco hijas: María Josefa (1877); Francisca de Paula (1880); María del Carmen (1881); Teresa (1884); y María Manuela (1887). Josefa de Zulueta y Samá falleció el 22 de junio de 1896. Francisco Romero pudo celebrar las bodas de dos de sus hijas: en 1902 Francisca casó con Mariano Ordóñez y García ${ }^{24 ;}$ y en 1904 María Josefa con Fernando Moreno de Tejada y Díaz de Cabria, IV Conde de Fuente Blanca ${ }^{25}$.

19 En 1882 a María Josefa se le adjudicó mediante la herencia de su padre Julián la cantidad de 535.265,26 pesos oro. Además, junto con sus tres hermanos — Salvador, Eduardo y Ernesto-, nacidos del primer matrimonio de su padre con Francisca Dolores Samá y Mota, recibió el ingeniero azucarero España, valorado en 1.424.659 pesos oro. Archivo Nacional de Cuba, Escribanía de González Álvarez, Testamento de Julián de Zulueta y Amondo, 6 de junio de 1878, legajo 39, n. 10. E. Marrero Cruz, Julián de Zulueta y Amondo..., pp. 149-150 y 217.

20 AHPM (Archivo Histórico de Protocolos de Madrid), Notaria de Antonio Turón y Boscá, Escritura de las operaciones particionales de los bienes al fallecimiento de Francisco Romero Robledo, 12-10-1906, PN43.180, folios 4.356r-4.482r.

21 Sobre este personaje, véase: E. Marrero Cruz, Julián de Zulueta y Amondo, promotor del capitalismo en Cuba, La Habana, Ediciones Unión, 2008.

22 Al respecto, cabe mencionar que Francisco Romero, al igual que su suegro Julián Zulueta, se dedicó a la producción de azúcar, también se preocupó por introducir la tecnología más avanzada en el ingenio San José de Antequera. Ambos fueron accionistas del Banco Hispano Colonial. E. Marrero Cruz, Julián de Zulueta y Amondo..., p. 146; F. J. García Ariza, "La construcción del Ingenio...". Según M. Rodrigo y Alharilla, "El Banco Hispano Colonial y Cuba", Illes i Emperis, 4 (2001), pp. 49 y 68, el Banco Hispano Colonial fue fundado "merced al empréstito concedido a la Hacienda española para solventar la primera guerra cubana de independencia" y se convirtió en "la herramienta instrumental de los integristas peninsulares para incidir en la definición de la política colonial española hacia Cuba".

23 A. Bahamonde y J. Cayuela, "Entre España y el mercado mundial. El clan de los Zulueta (1823-1885)", en Hacer las Américas: las elites coloniales españolas en el siglo XIX, Madrid, Alianza Editorial, 1992, pp. 223277; M. Rodrigo y Alharilla, "Con un pie en Catalunya y otro en Cuba: la familia Samá, de Vilanova", Estudios històrics i documents dels arxius de procolos, 16 (1998), pp. 359-398; U. Apaolaza Ávila, "Un análisis sobre la historiografía en torno al alavés Julián de Zulueta y Amondo", Estudios Alaveses, 18 (2003), pp. 121-140.

24 Mariano Ordóñez y García (1874-1938) fue abogado y político por las filas conservadoras y en varias ocasiones Ministro durante el reinado de Alfonso XIII. http://www.congreso.es/portal/page/portal/Congreso/ Congreso/SDocum/ArchCon/SDHistoDipu/SDIndHistDip?_piref73_1340024_73_1340023_1340023.next_ page=/wc/servidorCGI\&CMD=VERLST\&BASE=DIPH\&FMT=DIPHXLDA.fmt\&DOCS=1-25\&DOCORDER=FI FO\&OPDEF=Y\&QUERY=\%2882340\%29.NDIP (Consulta: 11-10-2018). De nuevo, el vínculo familiar también se manifestó en la participación de Ezequiel Ordóñez, padre de Mariano Ordóñez, en los intereses económicos de Francisco Romero ya que prestó a la Sociedad Azucarera Antequerana 150.000 pesetas, desde 1894 formó parte del Congreso de la Administración de la empresa en calidad de accionista, sabemos que en 1906 tenía 25.000 pesetas del capital de la azucarera. AHMA, FAE, ASAA: leg. 337, carpeta 16, Memoria de la Sociedad Azucarera Antequerana Año 1890-1893; libro 140, Actas de la Junta General Ordinaria de Accionistas de la Sociedad Azucarera Antequerana, 29 de junio de 1894, y Actas de la Junta General Extraordinaria de Accionistas de la Sociedad Azucarera Antequerana, 10 de diciembre de 1903.

25 AHPM, Notaria de Antonio Turón y Boscá, Escritura de las operaciones particionales de los bienes al 
La aportación de Francisco Romero Robledo a la "sociedad conyugal" consistió en un caudal de bienes valorado en 375.782 '75 ptas., procedentes de las mencionadas herencias y adquisiciones.

La aportación de María Josefa Zulueta al matrimonio fue cuantiosa y muy superior a la de su esposo ${ }^{26}$. Se cifró en 3.357.762'28 ptas. y consistió en:

a) En concepto de dote aportó una finca, "La Quinta Marianao", en la Isla de Cuba, valorada en 1.713.761'95 ptas. En 1896 fue vendida con un quebranto de 140.000 ptas., ocasionado por las consecuencias del proceso independentista cubano. Por lo tanto, esta aportación quedó en 1.573.761'95 ptas. ${ }^{27}$.

b) La herencia paterna, recibida en 1882 , valorada en $1.780 .824,90$ ptas., incluía la cuarta parte de un ingenio en Cuba.

c) Por la herencia de su tía María Cruz Zulueta, recibida en 1886, aportó 3.175'43 ptas.

Merced a los vínculos de su esposa con Cuba, Romero Robledo tuvo una estrecha relación con la Isla. Su mujer era hija del acaudalado hacendado Julián de Zulueta, poseedor de varios ingenios azucareros, trabajados por mano de obra esclava, y una cuarta parte de uno de ellos, el denominado "Ingenio España", que esta recibió por la herencia de su padre ${ }^{28}$. Desde entonces, Romero defendió a ultranza sus propios intereses, que también eran los de los esclavistas azucareros de la isla. Se convirtió en un acérrimo enemigo de la autonomía y obviamente de la independencia, así como en activo defensor de la esclavitud ${ }^{29}$. Sus relaciones con esta clase burguesa de Ultramar fueron intensas. Los españoles con haciendas y residentes en Cuba, a cuyo partido, la Unión Constitucional, pertenecía, le nombraron "compañero honorario". Su militancia activa contra la abolición de la esclavitud durante el sexenio democrático fue constante, desde puestos políticos o en la oposición a las medidas de la monarquía de Amadeo de Saboya y al gobierno presidido por Ruiz Zorrilla. Primero, en 1869 ocupó el puesto de Subsecretario de Ultramar pero después militó en la oposición a los sucesivos gobiernos progresista y radical de la monarquía democrática de Amadeo I. Participó en la conspiración para restablecer la dinastía borbónica y, tras el golpe de Estado de Martínez Campos, tomó las riendas del gobierno Cánovas del Castillo, su valedor, que lo tuvo de ministro de Ultramar entre el 31 de diciembre de 1874 y el 3 de enero de 1875 mientras que llegaba su titular, cargo que de nuevo ocupó unos días en julio de 1875. En 1891, siendo de nuevo Ministro de Ultramar, reorganizó la administración de la Isla con una orientación centralista, opuesta a cualquier tipo de concesión autonomista.

fallecimiento de Francisco Romero Robledo, 12-10-1906, PN43.180, folios 4.356r-4.482r.

26 Lo mismo le sucedió a Germán Gamazo con su matrimonio con Regina Abarca y Flejo, ella aportó como dote 672.009 pesetas, Gamazo 222.295 pesetas. E. Calzada del Amo, Germán Gamazo..., pp. 82-83.

27 La finca Marianao la había heredado de su tío abuelo Salvador Samá Martí (1797-1866), natural de Vilanova i la Geltrú, marchó a Cuba en 1811, donde heredó los negocios de su tío Pau Samá Parés, enriquecido con el tráfico de eslavos y la importación y exportación de vinos y azúcar. Salvador, pro-peninsular, se dedicó a los negocios, el comercio y las finanzas en la Habana, también fue refaccionista (almacenistas y comerciante que proveía al ingenio, concedía préstamos y cobraba al final de la zafra), en 1845 se instaló en el municipio de Marianao. Presidió la Junta Directiva de la Sociedad de Fomento de Marianao, Julián de Zulueta fue uno de sus socios. Esta sociedad hizo posible que Mariano pasase de ser un caserío a un floreciente pueblo y dispusiese de tren. AHPM, Notaría de Mariano García Sancha, Escritura de dote de M. Josefa Zulueta y Samá, 27-12-1875, PN31002, folios 8.392r-8.409r; E. Marrero Cruz, Julián de Zulueta y Amondo..., p. 49; Pérez Tarrau, D. M., La saga cubana de los Samà (1794-1933), Barcelona, Viena Ediciones, 2007, pp. 31, 123, 175, 204-205, 211 y 237.

28 AHMA, FAE, ASAA, leg. 226, carpeta 2, Partición de bienes al fallecimiento de Josefa Zulueta, 26-2-1897. 29 I. Roldán de Montaud, "La política española en Cuba: una década de cambios (1876-1866)", Ayer, 52 (2003), p. 191. 
En plena crisis de 1898 defendió la represión ejercida por el general Valeriano Weyler en Cuba. Además, tuvo una actitud beligerante contra Estados Unidos por su apoyo a los independentistas cubanos $^{30}$.

En paralelo, ya estando casado, Romero Robledo heredó de su abuela María Remedios Checa Navarrete, de su padre Matías Romero en 1878 y de su tío Vicente en 1886. De María Remedios recibió 5 casas en Antequera, valoradas en 8.635 pesetas en $1897^{31}$. De Matías heredó tres fincas que sumaron más de 500 fanegas de extensión, una casa en Antequera y 13.700 reales en créditos a favor del difunto, todo ello valorado en 338.106 reales en 1878, estas propiedades fueron tasadas en 72.101 pesetas en $1897^{32}$. Vicente falleció sin descendencia, declaró heredero universal a su sobrino Romero Robledo y dejó un pequeño legado a sobrina Concepción. Tal vez para evitar disputas por la herencia, en su testamento y participación de bienes no aparece una relación de estos, lo que no es habitual. Merced a la partición de bienes realizada con motivo del fallecimiento de Josefa Zulueta conocemos los bienes que heredó Francisco Romero de su tío, o al menos los que de él conservaba en 1897: dos casas en Antequera valoradas ese año en 15.750 pesetas $^{33}$.

En la partición de los bienes de María Josefa Zulueta y Samá, efectuada a principios de 1897, el caudal general de ambos cónyuges fue tasado en 4.336.579'08 ptas. Las "bajas" a dicho caudal fueron apreciadas en 3.958.081'93 ptas. De lo que resultó que el líquido ganancial de la sociedad conyugal ascendió a 378.497'15 ptas., que dividido entre los cónyuges, correspondió a cada uno 189.248,57 ptas., acumulado en veintiún años de casados $(1875-1896)^{34}$.

Como hemos comentado, hasta ahora se consideraba que Francisco Romero Robledo se había dedicado exclusivamente a la política. Pues bien, ahora sabemos que antes y durante su etapa de casado incrementó su patrimonio, comprando casas, fincas y apostando por un cultivo nuevo, la remolacha, y su transformación industrial, al fundar la Azucarera Antequerana. En definitiva, diversificó sus inversiones.

La tabla 1, basada en la partición de bienes de 1897 efectuada tras el fallecimiento de su esposa, refleja dicha diversificación ${ }^{35}$ y sus conexiones con Cuba. Asimismo, que solía haber un vínculo previo con los promotores de dichas empresas. De dicha tabla se colige la participación de Romero Robledo, por orden de importancia, en el sector del azúcar, la banca, la fabricación textil, el transporte marítimo, la minería y la obra pública.

30 A. Parejo Barranco, Francisco Romero..., p. 12.

31 Herencia resultante del expediente judicial aprobado por auto de 10 de septiembre de 1878. En el inventario post-mortem de María Remedios Checa sus bienes fueron valorados en 2'3 millones de reales de 1880. M. Fernández Paradas, Propios, Arbitrios..., p. 215. AHMA, FAE, ASAA, leg. 226, carpeta 2, Partición de bienes al fallecimiento de Josefa Zulueta, 27-2-1897.

32 AHMA, FPN, Notaría de Juan Antonio Betes Díaz, Descripción de bienes quedados por fallecimiento del Sor. D. Matías Romero y Mantilla, 9-10-1868, leg. 2.942, folios 959v-960v; y, FAE, ASAA, leg. 226, carpeta 2, Partición de bienes al fallecimiento de Josefa Zulueta, 27-2-1897.

33 AHMA, FPN, Notaría de Miguel de Talavera, Partición de bienes al fallecimiento de Vicente Robledo y Checa, 26-10-1886, leg. 2.956, folios 3.744r-3.755r; y, FAE, ASAA, leg. 226, carpeta 2, Partición de bienes al fallecimiento de Josefa Zulueta, 27 -2-1897.

34 AHMA, FAE, ASAA, leg. 226, carpeta 2, Partición de bienes al fallecimiento de Josefa Zulueta, 26-2-1897.

35 Una estrategia de diversificación que también puede verse en la composición de los bienes de Ramón Ybarra Arreguial en 1903, en P. Díaz Morlán, Los Ybarra. Una dinastía de empresarios 1801-2001, Madrid, Marcial Pons, 2002, p. 346. Por el contrario, Germán Gamazo optó por una estrategia diferente ya que su fortuna se fraguó en base a los ingresos generados por su bufete de abogados y el cobro y el recibo de deudas que destinó principalmente a la compra de fincas rústicas. E. Calzada del Amo, Germán Gamazo..., pp. 91, 152 y $430-431$. 
Tabla 1. Empresas en las que tenía participación Francisco Romero Robledo en 1897.

\begin{tabular}{|c|c|c|c|}
\hline Empresa & $\begin{array}{l}\text { Número } \\
\text { acciones }\end{array}$ & $\begin{array}{c}\text { Valor de las } \\
\text { acciones } \\
\text { (pesetas) }\end{array}$ & $\begin{array}{c}\% \text { valor } \\
\text { acciones }\end{array}$ \\
\hline $\begin{array}{c}\text { Sociedad } \\
\text { Azucarera } \\
\text { Antequerana }\end{array}$ & 600 & 300.000 & 32'15 \\
\hline $\begin{array}{l}\text { A. Sedó y } \\
\text { Compañía }\end{array}$ & 54 & 135.000 & $14 ' 47$ \\
\hline $\begin{array}{l}\text { Banco } \\
\text { Hispano } \\
\text { Colonial }\end{array}$ & 500 & 200.000 & $21 ' 43$ \\
\hline $\begin{array}{c}\text { Compañía } \\
\text { Trasatlántica } \\
\text { López Brú y } \\
\text { Cía. }\end{array}$ & 100 & 114.000 & $12 ' 22$ \\
\hline $\begin{array}{l}\text { Sociedad } \\
\text { Hullera } \\
\text { Española }\end{array}$ & 187 & 87.890 & $9^{\prime} 42$ \\
\hline $\begin{array}{c}\text { Ferrocarriles } \\
\text { Castro } \\
\text { Urdiales }\end{array}$ & 175 & 68.750 & 7'37 \\
\hline $\begin{array}{c}\text { Ferrocarriles } \\
\text { del Norte de } \\
\text { España }\end{array}$ & 200 & 23.560 & 2'52 \\
\hline $\begin{array}{l}\text { Sociedad } \\
\text { Constructora } \\
\text { del Puerto } \\
\text { de Málaga }\end{array}$ & s.d. & $7 \%$ * & s.d. \\
\hline $\begin{array}{c}\text { Minas } \\
\text { Buenas de } \\
\text { San Pedro }\end{array}$ & s.d. & 3.850 & 0’41 \\
\hline Total & 1.816 & 933.050 & $100 ’ 00$ \\
\hline
\end{tabular}

Fuente: AHMA, FAE, ASAA, leg. 226, carpeta 2, Partición de bienes al fallecimiento de Josefa Zulueta, 27 de febrero de 1897. Elaboración propia.

*Se refiere al \% del capital que tenía en la empresa. s.d.: $\sin$ datos.

Más de la mitad del valor de las acciones correspondían a la Sociedad Azucarera Antequerana y el Banco Hispano Colonial. La Azucarera Antequerana fue fundada el 18 de noviembre de $1890^{36}$ con el propósito de producir azúcar con remolacha, para promover la 
diversificación agraria y agroindustrial de Antequera y su comarca. Fue una respuesta a la crisis finisecular que estaba sufriendo ese territorio. Cabe reseñar la fuerte implicación de Romero Robledo, su fundador, en la toma de decisiones de la empresa. Pese a que residía en Madrid, fue presidente del Consejo de Administración desde su constitución hasta su fallecimiento. Vinculado con ello entre sus muchas inquietudes estuvieron la agricultura y las innovaciones técnicas que se ponen de manifiesto en las cartas que intercambió con su tío Vicente Romero y Checa ${ }^{37}$.

Figura 3. El Cortijo "El Romeral"

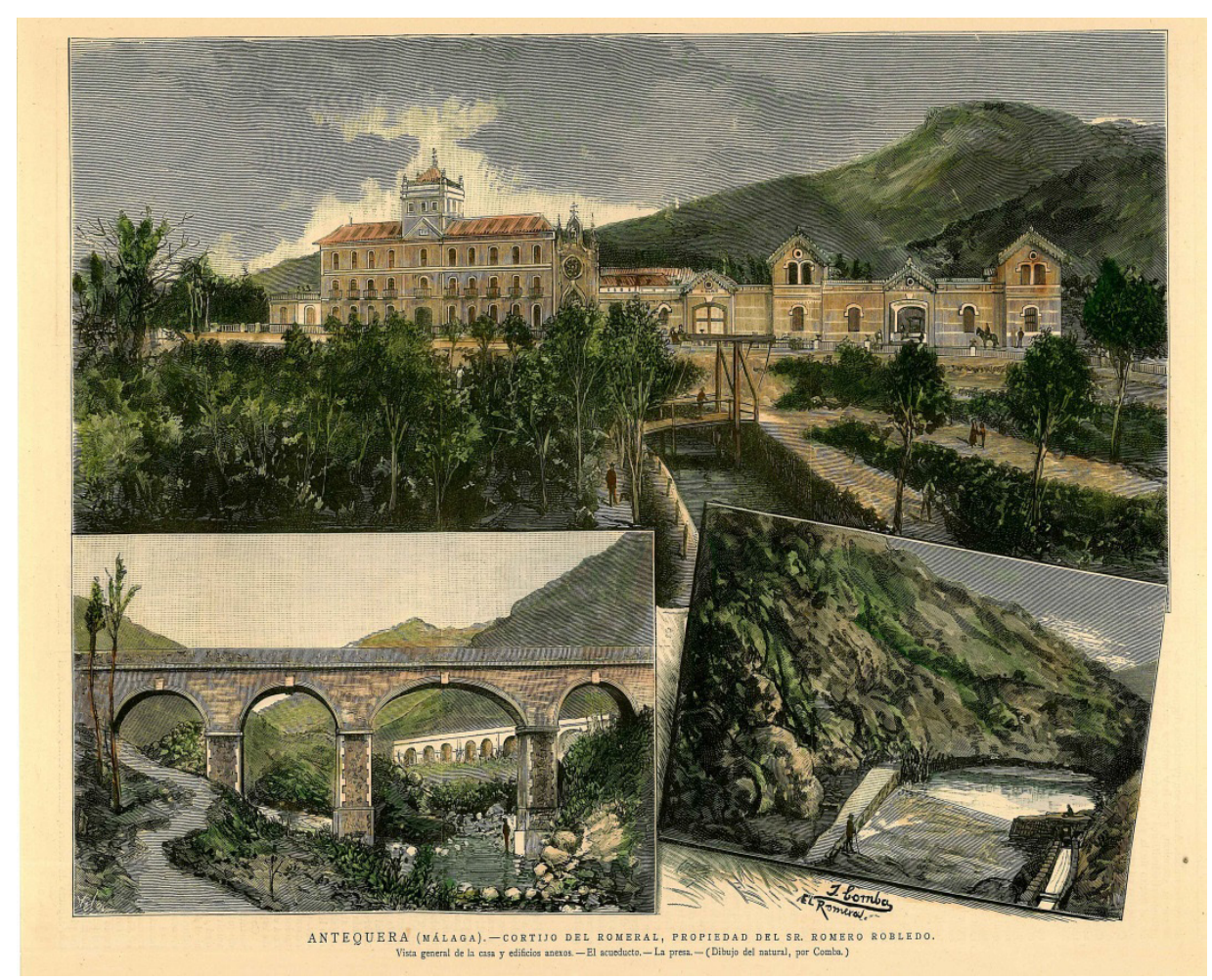

Fuente: AHMA.

¿Defendió Romero Robledo como político sus intereses empresariales? ${ }^{38} \mathrm{La}$ documentación conservada en el Archivo de la Sociedad Azucarera Antequerana nos permite responder a esta cuestión. La Ley de Presupuesto de 30 de junio de 1892 autorizó al Gobierno a celebrar conciertos por cuatro años con los productores de azúcar peninsulares, en base al rendimiento de la materia prima que estableció del 5\% para la remolacha y la

Talavera Muñoz, 18-11-1890, leg. 2.980, folios 2.454r-2.473v. Romero Robledo recurrió a familiares para crear la sociedad, en 1891 él controlaba el $24 \%$ de su capital y su familiares el 8,8\%. AHMA, FAE, ASAA, leg. 339, carpeta 32, Accionistas en diciembre de 1891.

37 F. J. García Ariza, "La construcción...". Vicente Romero Checa "labraba los cortijos de "El Romeral", "Blancares" y "Saucedilla", propiedad de Romero Robledo. AHMA, FAF, ARR, signaturas 11 y 71; y Fondo Municipal (FM), leg. 756, Amillaramiento de 1880-1881. En el Cortijo de "El Romeral" Romero Robledo pasó largas temporadas, atendiendo sus asuntos políticos y económicos. Fue lugar de reunión de los personajes más importantes de la Restauración.

38 Para las conexiones entre poder político y empresarial, ver el panorama general trazado en Mercedes Cabrera y Fernando del Rey Reguillo, El poder de los empresarios. Economía y política en la España del siglo XX (1875-2000), Madrid, Taurus, 2000. 
caña y el rendimiento de la superficie cultivada, con el ratio de 25 toneladas por hectárea ${ }^{39}$. Entre 1892 y 1899 el pago efectuado por la Sociedad Azucarera por dicho concierto se situó en torno al $6 \%$ del total de sus gastos ${ }^{40}$. Por Real Decreto de 9 de agosto de 1899 quedaron rescindidos los conciertos y se fijó que el azúcar producido en la península debía pagar 20 pesetas por 100 kg de azúcar. Francisco Romero, cuando el Congreso trató este asuntó se ausentó para eludir enfrentarse al Ministro de Hacienda, el conservador Raimundo Fernández Villaverde ${ }^{41}$. Ahora bien, en octubre de 1899 el Consejo de Administración acordó por unanimidad entablar por la vía Contenciosa demanda de la nulidad de dicha disposición ${ }^{42}$.

La Ley de Presupuestos de 5 de agosto de 1893 modificó la tributación de los alcoholes producidos con mieles ${ }^{43}$ españolas o de Ultramar, al establecer un impuesto de 37'50 pesetas por hectólitro. En la Memoria de 1892-1893 se dice que la Sociedad Azucarera había decidido recurrir a la influencia de personas de prestigio, ante el Ministro de Hacienda, Germán Gamazo Calvo, para que cambiara dicho tributo, lo que favorecería la venta de las melazas y mejoraría su precio. Parece ser que dichas gestiones no obtuvieron resultados positivos ya que no hubo cambios al respecto.

El Banco Hispano Colonial representaba los intereses de los españoles en Cuba ${ }^{44}$, partidarios de un férreo control sobre la colonia, por tanto, rechazaban la independencia. Desempeñó un papel clave en la financiación de la Sociedad Azucarera Antequerana. Entre 1891 y 1896, gracias a las gestiones de Romero Robledo, la sociedad obtuvo préstamos por un importe de 1.500 .000 pesetas $^{45}$.

También estaba vinculada con la Isla la Compañía Trasatlántica López Brú y Cía., dedicada al transporte marítimo. Su origen se remonta al año 1849, cuando Antonio López y López y Patricio de Satrústegui y Bris constituyeron la Compañía de Vapores Correos A. López. En 1857 fue refundada por los hermanos Antonio y Claudio López y López, Patricio y Joaquín Marcos de Satrústegui y Bris y Joaquín y Carlos Eizaguirre y Balli. Antonio López y López, Marqués de Comillas $^{46}$, fue el alma mater de esta empresa. En 1861 lograron la

39 M. Martín Rodríguez, Azúcar y descolonización. Origen y desenlace de una crisis agraria en la Vega de Granada. El "Ingenio de San Juan", 1882-1904, Granada, Universidad de Granada, 1982, pp. 27-227.

40 AHMA, FAE, ASAA, legajos 336 a 338 y 341, Memorias de la Sociedad Azucarera Antequerana. Años 1891-1892 a 1898-1899.

41 M. Martín Rodríguez, Azúcar y descolonización..., pp. 229 y 254-255.

42 El pleito llegó al Tribunal Supremo que sentenció que la azucarera estaba obligada a pagar desde el ejercicio de 1902. AHMA, FAF, ASAA: libro 141, Actas del Consejo de Administración de la Sociedad Azucarera Antequerana, 18 de octubre de 1899; y leg. 144, carpeta 13, Resolución definitiva del recurso contencioso administrativo contra Hacienda.

43 El principal residuo generado por la fabricación de azúcar de caña y de remolacha era la melaza.

44 Al respecto, véase E. Marrero Cruz, Julián de Zulueta y Amondo..., pp. 145-146.

45 AHMA, FAE, ASAA, libro 141, Actas del Consejo de Administración de la S.A.A., 2-6-1894.

46 El profesor Rodrigo y Alharilla ha analizado el patrimonio y los negocios de los Marqueses de Comillas, al respecto, véanse, entre otros: "El Banco Hispano Colonial y Cuba, 1876-1898", Illes i imperis: Estudios de historia de la sociedades en el mundo colonial y post-colonial, 4 (2001), pp. 49-70; "La Casa de Comercio de los Marqueses de Comillas (1844-1920): continuidad y cambio en el capitalismo español", en Fortuna y negocios. Formación y gestión de los grandes patrimonios (siglos XVI-XX), Valladolid, Universidad de Valladolid, 2002, pp. 251-273; y, Los marqueses de Comillas, 1817-1925: Antonio y Claudio López, Madrid, Lid Editorial, 2005. En este último estudio afirma que "los gerentes de A. López y Cía. se asociaron con una de las firmas mercantiles de la capital cubana: la sociedad de Samá Sotolongo y Cía". Sobre esta sociedad, también puede consultarse: D. M. Pérez Tarrau, La saga cuba de los Samá..., pp. 368-369. Recuérdese que Romero Robledo contrajo nupcias con Josefa Zulueta Samá. Los Comillas fueron los impulsores del Banco Hispano Colonial, del que Romero fue accionista y que concedió préstamos a la Sociedad Azucarera Antequerana. 
concesión de los contratos de transporte de pasaje y correo entre España, Cuba, Santo Domingo y Puerto Rico, a la que posteriormente se sumó el traslado de soldados a Santo Domingo y Cuba. El Marqués de Comillas también fue el principal impulsor de la Sociedad Hullera Española, otra de las empresas participadas por Romero Robledo.

En cuanto a A. Sedó y Compañía, fue promovida en 1881 por el conservador Antoni Sedó i Pàmies, quien fue elegido diputado en las elecciones de 1876, 1879, 1884 y $1891^{47}$. Salvador de Zulueta, cuñado de Romero Robledo, también fue accionista ${ }^{48}$. En 1885, cuando Romero abandonó las filas del partido de Cánovas, Antoni Sedó le siguió.

En los Ferrocarriles del Norte de España trabajaba su sobrino José María Bores Romero. Este era el principal accionista de Ferrocarriles Castro Urdiales. Francisco Romero también tenía el $7 \%$ de la Sociedad Constructora del Puerto de Málaga ${ }^{49}$, obra que Luis Vasconi Cano y José María Bores dirigieron entre 1889 y $1897^{50}$. José María Bores, después de una corta experiencia política, alternó los puestos oficiales en diferentes administraciones, como ingeniero, con actividades técnicas y de gestión en proyectos empresariales $^{51}$. Luis Vasconi era ingeniero de caminos, con José María Bores trabajó en las obras de ampliación del puerto de Málaga desde 1889 hasta su conclusión en $1897^{52}$. Vasconi participó en la creación de la Sociedad Azucarera Antequerana, con un capital de 75.000 ptas., suscribiendo 150 acciones. Desempeñó importantes responsabilidades en la empresa, por ejemplo, en la construcción de la fábrica de azúcar junto con Bores ${ }^{53}$.

\subsection{La etapa de viudo}

A continuación se analiza la fase de viudo de Romero Robledo (1896-1906). María Josefa Zulueta y Samá falleció en Madrid el 21 de junio de 1896, sin haber otorgado testamento. Por este motivo, fue preciso elaborar un expediente sobre su patrimonio, así como efectuar la liquidación de la sociedad de gananciales y proceder al reparto de la herencia. El importe del caudal de sus bienes fue valorado en 4.336.579'08 ptas. Del mismo, era necesario deducir las aportaciones de ambos cónyuges, los créditos en contra de la sociedad conyugal y los gastos de partición e impuestos de derechos reales. Todas estas partidas ascendieron a 3.958.801'93 ptas., los gananciales a 378.497'15 ptas., que divididos entre Francisco y María Josefa dio para cada uno la cantidad de 189.248'57 ptas., así quedó la liquidación de la sociedad conyugal. El caudal hereditario de Josefa de Zulueta estaba constituido por las aportaciones de la finada (3.357.762'28 ptas.) y la mitad de los gananciales que le correspondió (189.248'57 ptas.), ambos sumaron 3.547.010'85 ptas. De esta cantidad se restaron los gastos por su enfermedad, el traslado del cadáver, el funeral y las misas que importaron 70.000 ptas., quedando como caudal líquido hereditario

$47 \mathrm{http}: / /$ www.congreso.es/portal/page/portal/Congreso/Congreso/SDocum/ArchCon/SDHistoDipu/ SDIndHistDip?_piref73_1340024_73_1340023_1340023.next_page=/wc/servidorCGI\&CMD=VERLST\&BA SE=DIPH\&FMT=DIPHXLDA.fmt\&DOCS=125\&DOCORDER=FIFO\&OPDEF=Y\&QUERY=\%28107930\%29. NDIP (Consulta: 25-9-2018).

48 Francisco Romero fue miembro del Consejo Consultivo de A. Sedó y Cía. G. Dorel-Ferré, Les colònies industrials a Catalunya..., pp. 284 y 286.

49 V. M. Heredia Flores, V. Heredia Flores, "José Bores Romero, un ingeniero en la España de la Restauración", en Pensar con la Historia desde el siglo XXI. Actas del XII Congreso de la Asociación de Historia Contemporánea, Madrid, UAM Ediciones, 2015.

50 AHMA, FAE, ASAA, leg. 226, carpeta 2, Partición de bienes al fallecimiento de Josefa Zulueta, 26-2-1897.

51 M. J. Ramos Rovi, Diccionario..., p. 109. V. Heredia Flores, “José Bores Romero...", pp. 1.705-1.724.

52 V. M. Heredia Flores, "José Bores Romero...".

53 AHMA, FAE, ASAA, leg. 337, carpeta 1. Memoria de la S.A.A. de 31 de Julio de 1892. 
3.477.010'85 ptas., que se dividió de la forma determinada en la legislación, esto es, en tercios, correspondiendo a cada tercio 1.159.003'72 ptas. Con los dos tercios, 2.318.007'24 ptas., se formó el capital correspondiente a las legítimas, en él el viudo, en concepto de herencia legal de usufructo debía recibir una parte igual a sus hijas. Siendo estas cinco, a Romero le correspondía una quinta parte (463.601'45 ptas.), que se dedujeron de las 2.318.007'24 ptas. La diferencia resultante fueron 1.854 .405 '79 ptas., que quedaron para las hijas, que se sumó al tercio de libre disposición. Este, al no estar asignado a nadie, porque María Josefa no había testado, pasó a formar parte del capital hereditario, ascendiendo a 3.013.409'51 ptas., que se repartió entre los cinco herederas, quedando para cada una 602.081 '88 ptas.

El caudal de bienes de Francisco Romero Robledo, tras la partición de los bienes de su esposa, a principios de 1897, quedó valorado en 1.028.632'80 ptas., cifra resultante de sumar su aportación al matrimonio, su parte de gananciales y la herencia recibida de su esposa, a la que había que restar el pago de deudas:

a) Por su aportación al matrimonio 375.782 '75 ptas. más su parte de gananciales (189.248'57 ptas.), un total de 565.031'22 ptas.

b) Para pagar deudas 269.537 '00 ptas.

c) Por la herencia de su esposa 463.601 '48 ptas. $^{54}$.

Tras el fallecimiento de su esposa y hasta su muerte (1896-1906), Romero Robledo hizo nuevas adquisiciones de escasa importancia y enajenó y permutó dos fincas. Pese a que no realizó compras importantes en esta etapa, a principios del Novecientos era el primer contribuyente de Antequera con una fortuna basada en la fabricación de bayetas y el azúcar de remolacha, así como un extenso patrimonio territorial, con más de 2.800 hectáreas, la mayoría de ellas habían sido tierras municipales ${ }^{55}$.

Tras quedar viudo, Romero Robledo continuó diversificando sus inversiones. En octubre de 1906 se efectuó la partición de sus bienes. En la misma queda constancia de las inversiones que había realizado después de fallecer su esposa. En 1902, de la Compañía General Española de Alumbrado, Calefacción y Fuerza Motriz a base de Alcohol y sus derivados, constituida en 1900, se hizo con 200 acciones, de 500 pesetas cada una, si bien finalmente sólo desembolsó en efectivo el 45 \%, es decir, 45.000 ptas. De la Sociedad Ibérica, desconocemos a qué se dedicaba, 100 acciones, con un valor para cada una de ellas de 500 pesetas, expedidas a nombre de José María Bores Romero y transferidas por este a su tío el 17 de julio de 1902. De la Corporación Metalúrgica de San Juan de Alcaraz, 48 acciones, también a razón de 500 pesetas por acción, cuyo valor era nulo en 1906, fijándose a efectos fiscales el de 1.000 pesetas. De la Compañía de Ferrocarril de San Julián de Musques a Castro Urdiales y Traslaviña, 50 acciones, con el mismo valor cada una. De la misma empresa, otras 75 acciones, de 1.000 pesetas cada una, transferidas a Francisco Romero el 10 de mayo de 1905, como "garantía" por su cargo de Consejero en el Consejo de Administración. Como esta compañía se había declarado en suspensión de pagos, debido a que sus acciones no habían generado interés alguno y estaba pendiente de aprobación judicial el convenio presentado por la empresa a sus acreedores, no teniendo las acciones cotización oficial ni valor reconocido en el mercado, se le atribuyó un valor del

54 AHMA, FAE, ASAA, leg. 226, carpeta 2, Partición de bienes al fallecimiento de Josefa Zulueta, 26-2-1897. 55 A. Parejo Barranco, "Revolución liberal..., p. 153; M. Fernández Paradas, Propios, Arbitrios..., p. 254. En el caso de Romero Robledo su poderío como propietario se correspondió con su control político absoluto sobre Antequera y la provincia de Málaga. Entre 1876 y 1905 "Antequera se mostró como un cacicato estable y escasamente competitivo". Dominó el ayuntamiento, como demuestra la presencia en la alcaldía de Francisco Guerrero Muñoz durante más de dieciséis años. A. Parejo Barranco, Historia..., p. 373. 
10\% de su valor nominal, esto es, 15.000 ptas. Por último, una acción del Instituto Hispano Americano de Artes Gráficas, sin valor "efectivo" alguno, computado en 100 ptas.

Parece ser que se desprendió de las acciones en las empresas en las participaba en 1897, salvo las de la Sociedad Azucarera Antequera ${ }^{56}$ y la Sociedad Hullera Española que continuaban en su poder cuando falleció en 1906.

Según la partición de sus bienes, realizada en octubre de 1906, su valor ascendió a 1.347.255'31 ptas. $^{57}$. Las cargas por deudas, enfermedad, entierro, funeral y otros gastos sumaron 349.739'59 ptas., que descontadas del total del caudal dejaron un líquido disponible de 997.515'72 ptas. A esta cantidad habría que añadir los valores no incluidos en el "inventario general de bienes", un total de 169.435 ptas. por: 300 acciones de la Sociedad Azucarera Antequerana, valoradas en 75.000 ptas.; y 187 acciones de la Sociedad Hullera Española en 94.435 ptas. Todo su patrimonio fue repartido entre sus cinco hijas en dicha escritura de partición, casi a partes iguales ya que Josefa y Francisca recibieron respectivamente bienes por valor de 23.606'14 pesetas, Carmen y Teresa por 204.503'14 y Manuel por 211.042'73. Asimismo, cabe reseñar que en dicho documento se configuró una finca denominada Cortijo del Romeral, que incluía no solo el cortijo que había recibido esa misma denominación hasta entonces, también la mayor parte de las propiedades rústicas de Romero Robledo en Antequera, en proindiviso ${ }^{58}$.

Si a las 94.435 pesetas le agregamos la del líquido disponible (997.515'72), resulta un total de 1.166.950'72 ptas. Cantidad superior a la que Romero Robledo tenía en 1897, tras el fallecimiento de su esposa, que incluía su aportación al matrimonio, su parte de gananciales y la herencia de su esposa (1.028.632'70 ptas.).

Por lo tanto, su incremento patrimonial en los diez años de viudo fue de 138.317'92 ptas. (Tabla 2). De lo que colegimos que en esos años continuó interesándose por acrecentar su patrimonio.

Tabla 2. Evolución del valor del patrimonio de Francisco Romero Robledo (1875-1906)

\begin{tabular}{|c|c|}
\hline Años & Pesetas \\
\hline 1875 & $375.782 ' 75$ \\
\hline 1897 & $1.028 .632 ' 70$ \\
\hline 1906 & $1.166 .950 ' 72$ \\
\hline
\end{tabular}

Fuente: Véase texto. Elaboración propia.

56 En la partición de sus bienes realizada en 1906 se distribuyeron entre sus herederas 300 acciones de la Sociedad Azucarera Antequerana, el resto, recuérdese que al fundarse la empresa a Romero Robledo le correspondieron 650, fueron cedidas a sus hijas y cónyuges antes de su fallecimiento.

57 Esta cifra, si bien es elevada, es inferior a las de las mayores fortunas del país. Por ejemplo, a la de Germán Gamazo valorada en 2.000.156'33 pesetas en 1901, y a la de Ignacio de Figueroa Mendieta, fallecido en 1899, valorada en 46,'3 millones de pesetas, o el patrimonio de Estanislao Urquijo y Landaluce valorado en 1889 por 50 millones. E. Calzada del Amo, Germán Gamazo..., pp. 430-431; P. Díaz Morlán, Los Ybarra..., p. 153, nota 11.

58 AHPM, Notaria de Antonio Turón y Bosca, Escritura de las operaciones particionales de los bienes al fallecimiento de Francisco Romero Robledo, 12-10-1906, PN43.180, folios 4.356r-4.482r. 
Para finalizar, es preciso mencionar que sus últimos meses de vida estuvieron marcados por un escándalo político con motivo del proyecto de obra que planteó para mejorar los riegos de las fincas "El Romeral" y "El Río". Lo presentó durante el "Gobierno Azcárraga" al Ministerio de Agricultura, Industria, Comercio y Obras Públicas, con la finalidad de obtener la servidumbre de acueducto en los terrenos necesarios de dominio público y las subvenciones a las empresas constructoras de canales y pantanos de interés públicos para mejorar los riegos de esas fincas. Dichas subvenciones estaban contempladas en Ley de 27 de julio de $1883^{59}$. El proyecto fue aprobado mediante el Real Decreto del Ministerio de Agricultura, Industria, Comercio y Obras públicas de 25 de enero de $1905^{60}$. Se concedió a Romero una subvención de 282.120'34 ptas, el 50\% del presupuesto de las obras.

El decreto provocó un gran revuelo. Ese mismo día varios periódicos trataron el asunto. El Imparcial publicó un duro artículo contra el gobierno y Francisco Romero argumentando, con razón, que la Ley de 1883 solo contemplaba conceder subvención para obras de "interés público" para comunidades de regantes y comunidades de propietarios ${ }^{61}$. En la misma línea, El Liberal consideró que la concesión de la subvención había contribuido al "restablecimiento de las buenas relaciones entre el Gobierno y el Sr. Romero Robledo", es decir, daba a entender que este había recibido un trato de favor a cambio de no "atacar" al Gobierno ${ }^{62}$. El periódico conservador La Época defendió que la subvención era legal ya que estaba avalada por informes favorables emitidos por diversas instituciones y que no había vinculación alguna entre su concesión y la crisis del "Gobierno Azcárraga". A continuación reconocía que la ayuda no le correspondía puesto que la "concesión hecha a Romero Robledo constituía, si no de derecho, sí de hecho, una empresa de interés público, porque al aumentar y mejoras los riegos (...) se aumenta considerablemente la riqueza y se mejoran las condiciones económicas de la localidad, proporcionando al Estado un aumento en el haber público por la mayor cuantía de sus productos y contribuciones"63.

Es interesante hacer referencia a que la fianza para garantizar la ejecución de las obras consistió en títulos de deuda amortizable de Claudio López Brú, Marqués de Comillas, el propio Francisco Romero Robledo y su consuegro Ezequiel Ordóñez González ${ }^{64}$. Cuando falleció Francisco Romero, todavía no había percibido cantidad alguna del Estado por la subvención.

\section{CONCLUSIONES}

Esta investigación, basada en fuentes primarias e inéditas, da a conocer una faceta de la vida del político Francisco Romero Robledo tan decisiva como los mecanismos con los que forjó un enorme patrimonio. Utilizó tanto las herencias recibidas como su matrimonio con Josefa de Zulueta, de una poderosa familia de esclavistas cubanos, lo que le permitió ampliar su capacidad para comprar bienes y participar como accionista en empresas de

59 Gaceta de Madrid, 31-7-1883.

60 Gaceta de Madrid, 24-1-1905.

61 J. Ayala Pérez, Un político..., pp. 195-225. J. Campos Rodríguez, "1905, polémica subvención del gobierno a Francisco Romero Robledo", La Crónica, 21-2-2015. El mismo argumento está presente en un artículo de El Imparcial, 13-2-1905.

62 El Liberal, 25-1-1905.

63 J. Campos Rodríguez, "1905, polémica subvención del gobierno...".

64 Ezequiel Ordóñez fue diputado y senador. http://www.congreso.es/portal/page/portal/Congreso/Congreso/ SDocum/ArchCon/SDHistoDipu/SDIndHistDip?_piref73_1340024_73_1340023_1340023.next_page=/wc/se rvidorCGI\&CMD=VERLST\&BASE=DIPH\&FMT=DIPHXLDA.fmt\&DOCS=1-125\&DOCORDER=FIFO\&OPDEF $=$ Y\&QUERY=\%2882320\%29.NDIP (Consulta: 10-12-2018). 
sectores diversos. Fue una estrategia consciente para diversificar sus inversiones, y se hizo posible merced a sus vínculos familiares y al círculo de amigos políticos íntimamente vinculados con los poderes del Estado.

En definitiva, fueron decisivos los lazos con las redes del poder político. Así, el patrimonio heredado por Romero Robledo, su mismo matrimonio y la ampliación de riquezas que efectuó siempre estuvieron asociados y entreverados con las redes y oportunidades que ofrecían las instituciones del Estado liberal. No por casualidad fue una figura de extraordinario poder político durante la Restauración canovista. De hecho, su entrada como accionista en determinadas empresas cabe explicarse sobre todo por sus conexiones de parentesco y clientelares con destacadas figuras políticas y empresariales en dicho periodo. El escándalo que le afectó con motivo de la concesión en 1905 de una subvención del Ministerio de Agricultura, Industria, Comercio y Obras Pública constituye una prueba manifiesta de la constante ligazón que trabó en su vida entre poder político y riqueza económica en cuyo cruce siempre estuvo el Estado como palanca para incrementar el patrimonio, que en este caso fue palanca sin tapujos, directamente a través de una subvención económica que no le correspondía.

\section{BIBLIOGRAFÍA}

Apaolaza Ávila, R. "Un análisis sobre la historiografía en torno al alavés Julián de Zulueta y Amondo", Estudios Alaveses, 18 (2003), pp. 121-140.

Ayala Pérez, J., Un político de la Restauración Romero Robledo, Antequera, Biblioteca Antequerana de la Caja de Ahorros y Préstamos de Antequera, 1974.

Bahamonde, A. y Cayuela, J., Hacer las Américas: Las elites coloniales españolas en el siglo XIX, Madrid, Alianza Editorial, 1992.

Cabrera, M. y Rey Reguillo, F. del, El poder de los empresarios. Economía y política en la España del siglo XX (1875-2000), Madrid, Taurus, 2000.

Calzada del Amo, E., Germán Gamazo (1840-1901). Poder político y redes sociales en la Restauración, Madrid, Marcial Pons, 2011.

Campos Rodríguez, J., "1905, polémica subvención del gobierno a Francisco Romero Robledo", La Crónica, 21 de febrero de 2015.

Caro Cancela, D. (dir.), Diccionario biográfico de parlamentarios de Andalucía (1810-1869), tomo I, Sevilla, Centro de Estudios Andaluces, 2012.

Comellas, J. L., Cánovas del Castillo, Barcelona, Ariel, 1997.

Díaz Morlán, P., Los Ybarra. Una dinastía de empresarios 1801-2001, Madrid, Marcial Pons, 2002.

Dorel-Ferré, G., Les colònies industrials a Catalunya. El cas de la Colònia Sedó, Barcelona, L'Abadia de Montserrat, 1992.

Escalante Jiménez, J., Los escribanos en Antequera. Un análisis global (1475-1868). Tesis Doctoral, Universidad de Málaga, 2015.

Fernández Paradas, M., Propios, Arbitrios y Comunales El patrimonio territorial del Concejo de Antequera (siglos XV-XIX), Málaga, CEDMA, 2004.

García Ariza, F. J., Orígenes y consolidación de la Sociedad Azucarera Antequerana (18901906). Tesis Doctoral, Universidad de Málaga, 2015.

— "La construcción del Ingenio San José", Revista de Estudios Antequeranos, 19-20 (20162017), pp. 39-116.

Heredia Flores, V., "José Bores Romero, un ingeniero en la España de la Restauración", en Pensar con la Historia desde el siglo XXI, Actas del XII Congreso de la Asociación de Historia Contemporánea, Madrid, UAM, 2015.

Linares Rivas, A., La primera cámara de la Restauración: retratos y semblanzas, Madrid, 
Establecimientos tipográficos de J. C. Conde y Ca., 1878.

Marrero Cruz, E., Julián de Zulueta y Amondo, promotor del capitalismo en Cuba, La Habana, Ediciones Unión, 2008.

Martín Rodríguez, M. Azúcar y descolonización. Origen y desenlace de una crisis agraria en la Vega de Granada. El "Ingenio de San Juan", 1882-1904, Granada, Universidad de Granada, 1982.

Parejo Barranco, A., Historia de Antequera, Biblioteca Antequerana de la Caja de Ahorros, Antequera, 1987.

— "Revolución liberal y elites locales. Dos ejemplos antequeranos de la segunda mitad del siglo XIX", en Antequera. Memorias de una época. Cincuenta años de la vida de una ciudad a través de la fotografía, Antequera, Junta de Andalucía, Unicaja, 1998, pp. 139-184.

- Francisco Romero Robledo. Último político romántico. Ingenio de la Restauración (Antequera, 1838-Madrid, 1906), Antequera, Ayuntamiento de Antequera, 2006.

Pérez Tarrau, D. M., La saga cubana de los Samà (1794-1933), Barcelona, Viena Ediciones, 2007.

Pinto Tortosa, A. J., El medio agrario andaluz ante la llegada del liberalismo: las revoluciones de 1835 y 1836 en Antequera, Antequera, Ayuntamiento de Antequera, 2009.

Ramos Rovi, M. J., Romero Robledo y el parlamentarismo español, Madrid, Congreso de los Diputados, Dirección de Estudios, Análisis y Publicaciones, 2009.

- Diccionario biográfico de Parlamentarios Andaluces, (1876-1923), Sevilla, Universidad de Sevilla, 2013.

Rodrigo y Alharilla, Martín, "Con un pie en Catalunya y otro en Cuba: la familia Samá, de Vilanova", Estudis històrics i documents dels arxius de protocols, 16 (1998), pp. 359398.

— "El Banco Hispano Colonial y Cuba 1876-1898", Illes e Imperis, 4 (2001), pp. 49-70.

Roldán de Montaud, I., "La política española en Cuba: una década de cambios (18761886)", Ayer, 52 (2003), pp. 175-206.

Talavera Quirós, R., Familias Antequeranas, Ejemplar mecanografiado, 2014. 